\title{
(t)
}

\section{TRABALHO PROFISSIONAL DOS ASSISTENTES SOCIAIS NA SAÚDE NA CONTRARREFORMA ESTATAL}

\author{
PROFESSIONAL WORK OF SOCIAL WORKERS IN HEALTH POLICY IN THE \\ COUNTER-REFORMATION OF THE STATE
}

\author{
Gleiciane Viana Gomes \\ Liana Brito²
}

\section{RESUMO}

Este estudo visa analisar o trabalho profissional ${ }^{3}$ do Serviço Social na política de saúde, em uma instituição pública no município de Fortaleza (CE), no contexto da contrarreforma do Estado. Observa-se o processo de precarização da política de saúde, posto pela tendência de minimização dos gastos públicos na esfera social, que se manifesta inclusive nas condições de trabalho e na ausência de concursos públicos, além da ampliação dos trabalhadores terceirizados. Para a consecução do objetivo apresentado, foi realizada uma pesquisa de campo em uma instituição de saúde pública, de caráter quantiqualitativo, utilizando a entrevista estruturada e a observação simples como técnicas de coleta de dados e tendo os assistentes sociais da referida instituição como sujeitos pesquisados, perfazendo uma amostra de seis entrevistados. O Serviço Social na Instituição analisada, como parte desse contexto,

1 Mestranda em Serviço Social, Trabalho e Questão Social pela Universidade Estadual do Ceará (UECE) e assistente social da Universidade Federal do Ceará (UFC).

2 Doutora em Educação pela Universidade Federal do Ceará (UFC) e docente adjunta da Universidade Estadual do Ceará (UECE) dos cursos de Serviço Social (bacharelado e mestrado acadêmico).

3 Trabalho profissional no sentido adotado por lamamoto (2011), entendendo o Serviço Social como profissão inserida na divisão social e técnica do trabalho. 


\section{temporollis}

sofre nos últimos anos um processo de desgaste de sua capacidade de dar respostas às demandas postas no cotidiano hospitalar, como parte das refrações da questão social, aprofundadas no contexto da crise estrutural do capital. Apesar disso, o estudo aponta que, no quadro de minimização do Estado na saúde, os profissionais de Serviço Social conseguem desenvolver um trabalho profissional condizente com os princípios do Código de Ética e da Lei de Regulamentação da Profissão. Fica perceptível o compromisso ético-político em garantir, legitimar e promover os direitos dos usuários do SUS no espaço estudado, utilizando-se de um instrumental técnico qualificado que embasa seu trabalho, inclusive lutando contra os processos de privatização que vêm se dando nos espaços das instituições públicas brasileiros.

Palavras-chave: Política de Saúde. Sistema Único de Saúde. Contrarreforma do Estado. Trabalho Profissional do Serviço Social.

\section{ABSTRACT}

This study examines the professional work of social work in health policy in a public institution in Fortaleza, state of Ceará, having the counter-reformation of the State on healthcare system as context. It is observed the healthcare policy decline, caused by the decrease of public investments on the social field, which is expressed by the working conditions, the absence of public examinations and the increase of outsourced workers. For reaching the presented objective, a quantitative and qualitative field research took place in a public healthcare institution, using structured interview and simple observation as data gathering techniques and having the institution's social workers as subject, making a sample of six respondents. The Social Work of the institution analyzed, as part in this context, suffers a failing process in its capacity of giving answers to the demands of daily hospital routine in recent years, as one of the expressions of the social issue, worsened in the capital's structural crisis. Nevertheless, the research points that in the minimization of the State on healthcare the social workers can develop a professional work according to the principles of the Ethical Code and the Professional Regulatory Law. It is then noticeable the ethical-political commitment to secure, preserve and promote the SUS beneficiaries' rights in the studied space, using qualified technical instruments which bases its work, and also fighting privatization processes that are happening among the Brazilian public institutions.

Keywords: Health Policy. Single Health System. Counter-reformation of the State. Professional Work of Social Work.

Submetido: 05/06/2015.

Aceito: 26/11/2015.

\section{Introdução}

Com a Constituição Federal de 1988 foi estabelecida a criação do Sistema Único de Saúde (SUS). O SUS desponta pautado nos princípios básicos da Reforma Sanitária: equidade, universalidade, integralidade e participação social. É nesta Carta Magna que se estabelece no 


\section{tempordilis}

Brasil pela primeira vez o conceito ampliado de saúde ${ }^{4}$ e o de seguridade social ${ }^{5}$. Com isso, têm-se a possibilidade de ampliação de direitos sociais e de garantia de serviços no âmbito das políticas sociais. No entanto, nesse mesmo contexto, na década de 1990, observou-se um movimento em sentido contrário que o governo federal designa de Reforma Estatal, que para Behring e Boschetti (2008) representa de fato uma contrarreforma.

Para as autoras, as reformas do Estado ocorridas na sociedade burguesa são aquelas que historicamente estão vinculadas ao avanço progressivo nas conquistas sociais e na ampliação dos direitos. O que se tem no Brasil, a partir da década de 1990, é um retrocesso no campo dos direitos. Portanto, Behring e Boschetti (2008) utilizam o termo contrarreforma do Estado para designar esse processo de redirecionamento das políticas sociais com vistas à adequação econômica em contexto de crise do capital na década de 1990 e início do século XXI no Brasil.

Esta contrarreforma trata-se de um processo de retração dos gastos públicos das políticas sociais, justificado e posto em prática através dos ajustes neoliberais. Tais ajustes estavam orquestrados com as exigências dos organismos internacionais, como o Banco Mundial e o Fundo Monetário Internacional (FMI), presentes no Consenso de Washington (IAMAMOTO, 2008), com a preocupação central de criar mecanismos facilitadores do processo de reprodução e de acumulação ampliada do capital. No centro de tais orientações, têm-se como principais características: a privatização, a descentralização e a focalização das políticas sociais. Esses princípios de imediato atingiam as conquistas legais estabelecidas no movimento amplo da sociedade brasileira envolvida na elaboração e na aprovação da Constituição de 1988. Dessa forma, percebe-se o movimento imprimindo um retrocesso ante as conquistas sociais recém-criadas no país.

A atual configuração da saúde neste contexto no país é protagonizada pelo confronto de dois projetos: o Projeto da Reforma Sanitária, por meio do Sistema Único de Saúde (SUS) de cunho universa-

4 Este conceito concebe a saúde não apenas como ausência de doenças, mas também como resultante de um contexto sanitário, social, político e econômico.

5 A seguridade social é composta pelo tripé: saúde, previdência e assistência social. A saúde é direito de todos e dever do Estado. A previdência social é para quem a contribui. A assistência social é para quem dela necessita. 


\section{temporollis}

lista, e o Projeto de Saúde Privatista ou Articulado ao Mercado, tendo como principal ideologia a política neoliberal. Para Lessa (2003 apud FONSECA, 2010, p.24), este confronto posto pelo movimento desses dois projetos significa para a categoria profissional de Serviço Social um duplo processo. Por um lado, ele representa "[...] uma expansão do mercado de trabalho para os assistentes sociais na esfera da saúde pública, decorrente, principalmente do processo de municipalização" e do "aumento de postos de trabalho no SUS"; por outro lado, a municipalização da política de saúde não garante condições mínimas de implementação conforme a legislação, resultando num processo de "[...] precarização do trabalho no que se refere às relações trabalhistas e reduções salariais".

Por conseguinte, o Serviço Social como uma das profissões partícipes das políticas sociais, consequentemente da política de saúde, está intrinsecamente relacionado a esse contexto, sofrendo suas influências. Conforme Fonseca (2010, p.24):

O assistente social, assim como os demais profissionais que atuam nessa área, realiza o seu fazer profissional em condições difíceis, colocando-se como mediadores entre uma população miserabilizada demandante destes serviços públicos e o descaso das elites dominantes.

Para a realização desta pesquisa é fundamental o arcabouço legal do Serviço Social, composto pelas Novas Diretrizes Curriculares (1996), pelo Código de Ética Profissional (1993) e pela Lei de Regulamentação da Profissão (1993). Esta base legal é essencial para a compreensão da direção crítica da profissão sustentada no projeto ético-político profissional ${ }^{6}$ do Serviço Social e materializada na instituição investigada. Sobre esse arcabouço legal, Sarreta e Bertani (2011) informam que ele está em consonância com os princípios da Reforma Sa-

6 Conforme Paulo Netto (1999), os projetos profissionais apresentam a autoimagem de uma profissão, elegem os valores que a legitimam socialmente, delimitam e priorizam seus objetivos e funções, formulam os requisitos (teóricos, práticos e institucionais) para o seu exercício, prescrevem normas para o comportamento dos profissionais e estabelecem as bases de suas relações com os usuários de seus serviços, com as outras profissões e com as organizações e instituições sociais privadas e públicas. Por sua vez, o projeto ético-político do Serviço Social tem sua estrutura flexível, tem em seu núcleo central o reconhecimento da liberdade como valor central; propõe a construção de uma nova ordem social, sem exploração/dominação de classe; posiciona-se a favor da equidade, da justiça social e da cidadania; dá ênfase na formação acadêmica qualificada, visando à qualidade dos serviços prestados à população. 
nitária na busca pela efetivação da universalidade do acesso à saúde.

lamamoto (2008) expressa que a prática profissional busca fundamentar-se em três dimensões: a teórico-metodológica, a técnico-operativa e a ético-política, que se inter-relacionam e complementam o trabalho profissional no cotidiano das instituições.

Com isso, a presente pesquisa tem como objetivo analisar o trabalho profissional do Serviço Social em uma instituição de saúde em Fortaleza (CE), no contexto da contrarreforma do Estado. Para isso, busca-se delimitar a função do Serviço Social na política de saúde no contexto de minimização do Estado, identificar e analisar a estrutura do Setor de Serviço Social e o seu cotidiano do ponto de vista de sua instrumentalidade, analisando os limites e as possibilidades do Serviço Social nesta instituição em interlocução com os profissionais do setor, a seguir, detalharemos o percurso metodológico para obtenção desses objetivos.

\section{Percurso metodológico}

Os objetivos acima apresentados conduzem à realização de uma pesquisa7 de caráter quanti-qualitativo, de tipo bibliográfico e de campo. Para tanto, tomamos como técnicas de coleta de dados: a observação simples, com suporte no diário de campo, e a entrevista estruturada, com utilização de aparelho de gravação de áudio.

A equipe de Serviço Social desta instituição é composta por doze assistentes sociais. O processo de escolha dos entrevistados procurou englobar assistentes sociais com regime estatutário, caracterizado pelo vínculo empregatício efetivo com a instituição; com vínculo pela Consolidação das Leis Trabalhistas (CLT), através da contratação

7 Trata-se, esta pesquisa de um Trabalho de Conclusão de Curso (TCC) de graduação em Serviço Social pela Universidade Estadual do Ceará (UECE). A pesquisa de campo foi realizada nos meses de maio e junho de 2011. Por fim, desenvolveu-se com base nos pressupostos éticos outorgados pela Resolução nº 196/96 do Conselho Nacional de Saúde, sendo submetida e aprovada pelo Comitê de Ética em Pesquisa (CEP) da instituição, sob o protocolo de número 35/11. A participação dos sujeitos é consolidada por meio da assinatura do Termo de Consentimento Livre e Esclarecido (TCLE). Neste Termo, estão expressas as condições para a sua participação, constando objetivos e garantias de sigilo de identidade dos sujeitos. Para tanto, os assistentes sociais entrevistados são nomeados numericamente de um a seis. A devolutiva dos dados da pesquisa aos sujeitos pesquisados se apresentaram de dois modos, a saber: foram entregues duas cópias impressas do TCC - uma para o CEP da instituição e outra para a equipe de Serviço Social do locus pesquisado. 


\section{temporolis}

por uma fundação; e residentes. Também se busca fazer uma mescla entre profissionais que têm mais tempo de serviço na instituição e profissionais com menos tempo.

A análise e interpretação dos dados coletados fizeram-se por meio da técnica Análise de Conteúdo de Bardin, explorada por Minayo (2007). Para a referida autora, essa técnica costuma apresentar três etapas: pré-análise (organização do material); exploração do material (codificação); e tratamento dos resultados, inferência e interpretação (categorização). Por essa análise, observamos quatro eixos centrais para discussão: trabalho profissional do Serviço Social na saúde, estrutura do setor de Serviço Social, competências para uma prática profissional crítica e ações profissionais do assistente social na saúde.

\section{Serviço Social na saúde}

Concomitantemente às políticas de saúde implantadas em 1930, há o surgimento do Serviço Social no Brasil como profissão inserida na divisão social e técnica do trabalho (IAMAMOTO, 2011). No âmbito hospitalar no Brasil, conforme Lessa (2003), o primeiro hospital a incorporar assistentes sociais foi o Hospital das Clínicas da Faculdade de Medicina da Universidade de São Paulo (USP), em 1943. Nesta conjuntura, o assistente social concentra-se no âmbito da assistência médica hospitalar, com vistas a ser um elo entre o serviço prestado, que é excludente e seletivo, e o usuário.

Nesse período, constatou-se que o assistente social tem uma condição paramédica, subsidiária aos ditames do saber e do trabalho médico, institucionalizado através da cooperação vertical na saúde, em que a dinâmica do trabalho coletivo organiza-se de forma hierárquica (LESSA, 2003). O Serviço Social cresce, por conseguinte, "quantitativamente como profissão inserida no núcleo de execução do modelo assistencial, individual, curativo e hospitalocêntrico de saúde", Mendes (1994 apud LESSA, 2003, p. 68), mantendo esse mesmo direcionamento em meio à ditadura militar (KRÜGER, 2010).

No atual contexto da política de saúde no Brasil, percebe-se o confronto entre uma proposta de saúde universal, expressa pelo SUS, e outra de cunho neoliberal. É neste contexto que se insere o Serviço Social, como profissão partícipe dessa política, reconhecido como uma das treze categorias da saúde de acordo com a Resolução n 218 , de 6/3/1997, além da Resolução do CFESS n³ 383, de 29/3/1999, junto 


\section{tempordilis}

a biólogos, profissionais de Educação Física, enfermeiros, farmacêuticos, fisioterapeutas, fonoaudiólogos, médicos, médicos veterinários, nutricionistas, odontólogos, psicólogos e terapeutas ocupacionais.

O assistente social está inserido nesse processo coletivo do trabalho nos serviços de saúde, sua utilidade, então, se dá pela dinâmica de cooperação entre os seus diversos profissionais, constituindo-se, de acordo com Costa (2000), o caráter multidisciplinar do trabalho. O que se procura adotar no SUS é a cooperação horizontal em detrimento da vertical, utilizada nos modelos de saúde anteriores ao SUS, em que há uma hierarquização das categorias profissionais de saúde.

\section{Trabalho profissional do Serviço Social na saúde}

A instituição de saúde analisada, situada no município de Fortaleza, é parte integrante de uma das universidades públicas. Possui tanto profissionais com vínculo estatutário, quanto profissionais vinculados a uma fundação, com base no regime da Consolidação das Leis Trabalhistas (CLT).

Como uma instituição de assistência à saúde, especificamente da saúde da mulher, e vinculada ao ensino superior, está ligada, respectivamente, ao Ministério da Saúde (MS) e ao Ministério da Educação (MEC). Por isso, possui como principais áreas de atuação as de ensino, pesquisa e assistência médica ginecológica e obstétrica. Seu público-usuário é, preferencialmente, pacientes com gravidez de alto risco, como: adolescentes, mulheres de idade mais avançada e muIheres com complicações na gravidez (pressão alta, problemas cardíacos, respiratórios, dentre outros).

O Setor de Serviço Social possui doze assistentes sociais, que trabalham 30 horas semanais ${ }^{8}$, sendo que oito são servidores efetivos, dois são funcionários da fundação e dois estão cursando a Residência Integrada Multiprofissional em Atenção Hospitalar à Saúde (Resmulti) ${ }^{9}$.

8 Conforme o Projeto de Lei - PL n 12.317, que fixa a carga horária máxima dos assistentes sociais em 30 horas semanais, aprovado em agosto de 2010, no final do governo Lula.

9 A Resmulti é um programa de residência, com bolsas de estudo disponibilizadas pelo MEC. No período da pesquisa, a instituição contava com dezesseis estudantes-residentes: dois assistentes sociais, seis enfermeiros, dois farmacêuticos, dois fisioterapeutas, dois nutricionistas e dois psicólogos. Cabe salientar que esta residência 


\section{temporollis}

perfil:

Num universo de doze profissionais, identifica-se o seguinte

Tabela 1 - Perfil dos assistentes sociais na Instituição

\begin{tabular}{|c|c|c|c|}
\hline $\begin{array}{l}\text { Ordem de } \\
\text { Profissionais }\end{array}$ & $\begin{array}{l}\text { Tempo de Serviço } \\
\text { na Instituição }\end{array}$ & $\begin{array}{l}\text { Tipo de Vínculo } \\
\text { Empregatício }\end{array}$ & $\begin{array}{l}\text { Trabalha em outra } \\
\text { instituição? Se sim, } \\
\text { onde? }\end{array}$ \\
\hline 1 & 25 anos & Servidor Público & ---- \\
\hline 2 & 25 anos & $\begin{array}{l}\text { Contratado, via } \\
\text { Fundação }\end{array}$ & $\begin{array}{l}\text { Prefeitura Municipal - } \\
\text { num Hospital }\end{array}$ \\
\hline 3 & 24 anos & Servidor Público & ---- \\
\hline 4 & 23 anos & Servidor Público & $\begin{array}{l}\text { Prefeitura Municipal - } \\
\text { num Hospital }\end{array}$ \\
\hline 5 & 22 anos & Servidor Público & NUTEP \\
\hline 6 & 22 anos & $\begin{array}{l}\text { Contratado, via } \\
\text { Fundação }\end{array}$ & $\begin{array}{l}\text { Prefeitura Municipal- } \\
\text { num Hospital }\end{array}$ \\
\hline 7 & 20 anos & Servidor Público & ----- \\
\hline 8 & 7 anos & Servidor Público & ---- \\
\hline 9 & 7 anos & Servidor Público & ---- \\
\hline 10 & 7 anos & Servidor Público & $\begin{array}{l}\text { Prefeitura Municipal - } \\
\text { num CAPS }\end{array}$ \\
\hline 11 & 1 ano e 5 meses & Residente - MEC & ---- \\
\hline 12 & 5 meses & Residente - MEC & ----- \\
\hline
\end{tabular}

Fonte: Dados coletados pela própria pesquisadora.

Deste perfil, temos:

1) Oito assistentes sociais são efetivos e estáveis, desse grupo, cinco possuem 20 ou mais anos de trabalho, e três estão com 7 anos de instituição, trabalhando também em outras instituições públicas municipais: em um Hospital, no Centro de Atenção Psicossocial (CAPS) e no Núcleo de Tratamento e Estimulação Precoce (NUTEP). Desse grupo de três, identificam-se outros vínculos trabalhistas, dois são servidores estatutários de Prefeituras Municipais e um tem contrato de trabalho regido pela CLT.

é de duração de dois anos. 
2) Dos dois profissionais com mais de 20 anos na Instituição e contratados por uma Fundação conveniada, identificamos que trabaIham em outras Instituições como servidores efetivos de Prefeituras Municipais, lotados em Hospitais públicos.

Deste quadro exposto, em relação aos profissionais da Fundação conveniada ao Hospital, embora não sejam efetivos, pode-se afirmar que eles têm certa estabilidade, pois ambos estão há mais de 20 anos nesse trabalho. Trata-se de uma realidade bastante diferenciada da tendência posta atualmente, marcada pela rotatividade tão presente na configuração do mercado de trabalho (IAMAMOTO, 2008). Por outro lado, pode-se também afirmar que a falta de novas contratações por parte da Fundação no setor de Serviço Social que, embora apresente aumento da sua demanda, em duas décadas este setor amplia o quadro em três profissionais, todos com vínculo estatutário, conforme o quadro expresso.

\section{Estrutura do Setor de Serviço Social na instituição}

O Serviço Social, objeto da pesquisa, foi criado apenas em 1985, embora a Instituição esteja em atividade desde 1965. Os assistentes sociais, aos poucos, vão consolidando o setor na instituição, inicialmente realizando atividades em horário comercial ( $8 \mathrm{~h}$ - 17h); porém, para responder às demandas, passam a se estruturar em regime de 24 horas por dia, durante toda a semana. No final dos anos de 1990, o setor perdeu sete assistentes sociais, vinculadas à Fundação, com contratos via CLT. Com esse corte de pessoal fica difícil garantir a cobertura dos plantões. Por este motivo, o setor passa, então, a realizar suas atividades apenas no período diurno (7h - 19h). Isso representa, de fato, o processo de precarização que passam a viver desde então. Em 2011, esse contexto ainda persiste. Percebe-se um retrocesso para a categoria profissional, representado pela perda de espaço sócioocupacional.

A equipe do Serviço Social atua em diversos tipos de atendimentos sociais à população usuária, nos seguintes locais: nas unidades de internamento - observação obstétrica, puerpério, oncologia, ginecologia e mastologia; na Unidade de Tratamento Intensivo (UTI) - Materna e na Neonatologia; nos ambulatórios - Planejamento familiar, Serviço de adolescente e Projeto Nascer, bem como na emergência e na sala de parto. 


\section{temporollis}

Em relação às condições de infraestrutura, considerando toda a complexidade de atendimento que o Serviço Social realiza, observase que o setor dispõe de uma sala específica e ampla com a estrutura básica necessária. No entanto, uma questão abordada por um Assistente Social (AS-2) é a falta de um espaço reservado que preserve o sigilo nos momentos de atendimento individual, conforme Resolução CFESS n 493/2006, de 21 de agosto de 2006. Essa Resolução é clara quanto às condições éticas e técnicas do exercício profissional da categoria e em seus artigos $2^{\circ}$ e $3^{\circ}$ expõe que:

Art. $2^{\circ}$ - O local de atendimento destinado ao assistente social, deve ser dotado de espaço suficiente, para abordagens individuais ou coletivas, conforme as características dos serviços prestados, e deve possuir e garantir as seguintes características físicas: a- iluminação adequada [...]; b- recursos que garantam a privacidade do usuário [...]; c- ventilação adequada [...]; d- espaço adequado para colocação de arquivos para a adequada guarda de material técnico de caráter reservado (CFESS, 2006).

Art. $3^{\circ}$ - $\mathrm{O}$ atendimento efetuado pelo assistente social deve ser feito com portas fechadas, de forma a garantir o sigilo (CFESS, 2006).

O Código de Ética de 1993 também dispõe sobre o sigilo profissional, no Capítulo V - Do Sigilo Profissional, abrangendo do artigo 15 ao 18, que versa sobre o atendimento mais reservado. O Assistente Social (AS-4) fala que a sala da Ouvidoria, que se localiza ao lado da sala do Serviço Social, fica disponível para um atendimento mais sigiloso, quando necessário. No entanto, essa não é a situação ideal, que permita autonomia e liberdade para a realização de atendimentos com privacidade aos usuários e à sua família.

Nas entrevistas, indagando sobre os atendimentos realizados pelo Serviço Social, os assistentes sociais entrevistados colocam que devido a um quadro de profissionais reduzido isso reflete sensivelmente na qualidade dos serviços prestados.

Aqui no Serviço Social, por exemplo, têm pouquíssimos profissionais, e assim, o trabalho acaba sendo precarizado de certa forma, pela falta de profissionais, porque não conseguimos dar conta de todas as demandas que são apresentadas para a nossa categoria, às vezes, por falta de profissional, por falta de materiais, então é bem difícil. Olha, eu acho a equipe muito mínima para dar conta de toda a de- 
manda (AS-3).

Para tentar minimizar a falta de profissionais, por vezes, o auxiliar administrativo, que possui graduação em Serviço Social, faz atendimentos de competência do assistente social, caracterizando a existência do trabalhador polivalente ou multifuncional.

O trabalhador polivalente é:

[...] chamado a exercer várias funções, no mesmo tempo de trabalho e com o mesmo salário, como consequência do enxugamento do quadro de pessoal das empresas. $O$ trabalhador deixa de ser um trabalhador 'especializado' [...] sendo solicitado a exercer múltiplas tarefas, até então não necessariamente envolvidas em suas tradicionais atribuições (IAMAMOTO, 2008, p.32).

Outro elemento que merece destaque, revelando a realidade de precarização do Serviço Social no Hospital, afetando a atuação profissional, é a presença de diversos tipos de vínculos empregatícios. Tem-se, por exemplo, que dos doze assistentes sociais, oito são com regime estatutário, dois com contrato via CLT e dois com bolsa da Residência disponibilizada pelo MEC. Os dois profissionais com vínculo com a Fundação contratados via CLT, ganham em média, conforme suas falas, quatro vezes menos do que os efetivos da Instituição Pública. Analisando essa realidade, comparando com os dois residentes, a situação é ainda mais precária, pois os residentes também contam com uma remuneração superior dos contratados pela Fundação. Além disso, eles não possuem alguns dos direitos que os efetivos possuem, como o Adicional por Plantão Hospitalar (APH)..$^{10}$

Explicitado as condições estruturais de infraestrutura e de trabalho do Serviço Social na Instituição, a seguir serão discutidas as competências para uma prática crítica do assistente social na saúde, outro eixo central de discussão da pesquisa.

\section{Competências para uma prática profissional crítica}

Segundo lamamoto (2008), para uma prática profissional crítica, o assistente social deve ter domínio de três competências: a teóri-

10 Na Instituição, o valor de um APH corresponde a cerca de um Salário Mínimo bruto. Para o setor de Serviço Social é oferecido por mês oito APHs, o que corresponde a cada profissional efetivo. Cabe salientar que o APH corresponde a um plantão de 12 horas. 


\section{temporollis}

co-metodológica, a ético-política e a técnico-operativa.

A competência teórico-metodológica diz respeito ao profissional visualizar e compreender a dinâmica da sociedade na qual está inserido assim como a Instituição em que trabalha. Dessa forma, o desafio é sair da aparência imediata da realidade para adentrar a sua essência. Observamos essa questão presente nas preocupações dos profissionais entrevistados, vejamos:

[...] por conta de todos os problemas estruturais, históricos da nossa sociedade, da falta de oportunidades, de educação, desemprego, do desinteresse realmente de governo, de política de governo, de políticas públicas, então, assim eu acho muito difícil trabalhar na saúde nesse contexto em que vivemos de pouca oportunidade, trabalhamos no serviço terciário [...], temos um terreno até razoável, mas sentimos hoje muitos reflexos disso tudo (AS-4).

Ficam evidenciados os limites postos à prática profissional pela causalidade posta pelo contexto da flexibilização das relações de trabalho e da precarização das políticas públicas, o que recai sobre a condição dos usuários que demandam serviços sociais e sobre os próprios assistentes sociais como trabalhadores assalariados, limitados também pelas condições objetivas precarizadas das instituições públicas. Ambos, usuários e assistentes sociais, vivenciam os desdobramentos dessa realidade tanto em suas condições de vida e de trabalho.

Krüger (2010, p.142) relata que para a competência teórico-metodológica "é imprescindível que a ação profissional esteja sustentada no conhecimento da realidade dos serviços e das necessidades dos sujeitos para as quais são destinadas".

É fundamental na competência ético-política que o assistente social, para ter sua prática baseada em uma direção social, tenha um posicionamento político diante das questões que aparecem na realidade social, tendo como base as orientações do Código de Ética. Essa questão foi apontada em várias falas dos entrevistados:

A nossa prática é baseada nos valores do Código de Ética, está garantindo direitos, respeitando os usuários igualmente, aceitando as diferenças. Tem que ir ao encontro do que o Código preza (AS-1).

A prática do assistente social na saúde é muito difícil, muito difícil e contraditória, certo?! Porque a nossa atuação aqui, 


\section{tempordils}

o público que a gente atende, na verdade, é um público que geralmente vem de uma classe social desfavorável [...]. Então assim, a nossa categoria aqui enfrenta, para garantir os direitos dos usuários, desses pacientes, outras questões da instituição para poder estar garantindo esses direitos. E na nossa prática a gente procura sempre estar trabalhando, ou espera trabalhar com o projeto ético-político, de estar legitimando, de estar garantindo, fazendo a articulação com o nosso Código de Ética, com as Diretrizes Curriculares (AS3).

O Código de Ética é a água que a gente bebe todo dia (AS-5).

São os seus princípios que norteiam a prática do assistente social e possibilitam que possamos desenvolver o trabalho realmente coerente e voltado para o interesse de seus usuários (AS-6).

Na competência técnico-operativa, o assistente social tem o desafio e a possibilidade de criar um conjunto de habilidades técnicas que fundamentem sua prática perante os usuários e a instituição empregadora, considerando sua inter-relação com as dimensões teóricometodológica e ético-política, como unidade na diversidade. Destacase, nessa dimensão, a fala do Assistente Social (AS-5).

Ao longo dos anos a categoria vem aperfeiçoando cada vez mais essa prática, trazendo realmente suporte de referência técnico-instrumental, e para isso, eu diria com toda a tranquilidade de que para toda e qualquer ação de atividade, o Serviço Social, ele exige o instrumental que baliza a essa prática.

Na competência técnico-operativa, o Serviço Social conta com instrumentos diretos ou orais, indiretos ou escritos, que estão presentes no cotidiano profissional. Estes não estão desligados, como anteriormente posto, das dimensões ético-política e teórico-metodológica da instrumentalidade, como exposto por lamamoto (2004 apud SOUSA 2008). Com base nisso, os instrumentos orais ou diretos destacados do Serviço Social na Instituição estudada são: a observação participante, utilizada para (re)construir o instrumental; a entrevista individual e grupal; a dinâmica de grupo; e a reunião. Os instrumentos escritos ou indiretos são: as listas dos pacientes internados (incluindo gestantes, parturientes, recém-nascidos ( $R N$ ), e mulheres com doenças ginecológicas); e o controle de óbitos e de mães que saíram de alta hospitalar e deixaram seu RN no berçário. 


\title{
temporollis
}

Acrescentando-se a eles, o setor conta com as atas de reunião; os livros de registro, neles estão as atividades realizadas por assistente social no seu plantão, importante na continuidade das ações do cotidiano de trabalho; os relatórios e os pareceres sociais, com vistas a dar encaminhamento dos usuários para a rede social, como, por exemplo, os encaminhamentos de recém-nascido para o Conselho Tutelar, no caso de a mãe desejar deixá-lo para adoção; o instrumental do auxílio funeral; as estatísticas do atendimento do setor na instituição; dentre outros.

Todos esses instrumentos, diretos e indiretos, fundamentam e dão concretude ao trabalho do Serviço Social na Instituição, como uma instrumentalidade que se materializa na relação das finalidades do setor conformes às condições objetivas em que se encontram. Considerando a dinâmica contraditória da própria realidade (ARAÚJO, 2003) permitindo sempre a descoberta de novas possibilidades de melhoria do trabalho profissional e da vida dos usuários. Este trabalho tem sido baseado nos preceitos que guiam a profissão, como a Lei de Regulamentação da Profissão e o Código de Ética, como sempre expresso nas falas dos assistentes sociais.

No entanto, numa das falas dos entrevistados, percebemos uma visão fatalista da prática profissional, resultado de uma deficiência na relação entre as competências teórico-metodológica, técnico-operativa e/ou ético-política, conforme expressa abaixo:

\begin{abstract}
Eu não consigo enxergar por mais que se discuta, quando sai daquela sala lá de discussão, quando volta para o seu setor de trabalho, a prática volta a ser aquela prática que reforça, o quê? Que reforça o sistema neoliberal. Não tem nada de revolta, não tem nada de questionamento, de reflexão [...] A gente aceita como as coisas estão [...]. Não sei que prática seria essa de diferente, sabe?! Então fica difícil visualizar mudanças aqui claramente, nós estamos imersos e a gente representa a classe dominante, mesmo sem querer estamos reproduzindo na nossa prática o que estão colocando aí, o que o neoliberalismo está colocando. [...] Ele está reproduzindo tudo, eu me sinto assim na minha prática. O que o poder está mandando aí, não adianta ser ingênua e dizer que você vai ser contra. [...]. Eu não sei se eu sou pessimista não, mas eu não vejo assim: 'Ah, mas na sua prática você pode assim tentar arranjar uma brecha' (AS-2).
\end{abstract}

Não podemos deixar de considerar que essa análise do espaço profissional revela parte da realidade presente sob a política neolibe- 


\section{tempordils}

ral, com seus rebatimentos sobre o espaço institucional. Isso produz essa condição de impotência do profissional comprometido com o Projeto Ético-Político e limitado por uma materialidade posta que se assume determinante. A análise de Marx (1989) acerca da alienação do trabalhador sob o capital nos ajuda a perceber a condição profissional limitada pela realidade maior presente na Instituição e na política pública. No entanto, como diria Lukács (1978) essa realidade é uma causalidade posta pela dinâmica da sociedade que, em última instância, é desdobramento das escolhas dos homens, portanto é produto da práxis social dos homens. Dessa forma, não estamos diante de uma natureza dura, imutável, mas de uma realidade dialética e contraditória em permanente movimento. Nesse sentido, fica o desafio permanente para os assistentes sociais e para a categoria profissional de se apropriar desse movimento que é a realidade social e, pela mediação de sua instrumentalidade, ir contribuindo na melhoria das relações sociais em geral, institucionais e das políticas públicas.

Apreendemos que o assistente social é desafiado permanentemente nas suas competências no contexto de contradição expresso na política de saúde. As respostas por um lado podem ser de ordem imediatistas, sem reflexão, limitando o trabalho profissional e conduzindo a crises de identidade, de outro podem ser construídas na reflexão crítica da sua própria condição de trabalho e, coletivamente, ir em busca de alternativas postas pela dinâmica dialética do real.

Para finalizar os eixos centrais de discussão, apresentaremos o próximo item: ações desenvolvidas pelo Serviço Social na Instituição de saúde pesquisada.

\section{Ações desenvolvidas pelo Serviço Social em uma instituição de saúde}

O trabalho profissional do assistente social na saúde "[...] se dá através da compreensão dos aspectos sociais, econômicos e culturais que interferem no processo saúde, doença e a busca de estratégias para o enfrentamento destas questões." (CFESS, 2009, p.12). Com base nisso, o CFESS (2009) elaborou um documento intitulado "Parâmetros para a atuação de assistentes sociais na saúde", composto por seis ações profissionais"1" a dizer: assistencial; em equipe;

11 A ação profissional, conforme Nogueira e Mioto (2007, p. 281) é o "[...] conjunto de procedimentos, atos, atividades pertinentes a uma determinada profissão e realizadas por sujeitos/ profissionais de forma responsável, consciente", contendo 


\section{temporollis}

socioeducativa; mobilização, participação e controle social; investigação, planejamento e gestão; e assessoria, qualificação e formação profissional.

Essas ações profissionais "[...] constituem um instrumento importante na construção de estratégias para o exercício profissional e a busca de alternativas efetivas visando o atendimento das necessidades sociais apresentadas pelos usuários nos serviços de saúde." (SARRETA; BERTANI, 2011, p. 49).

As ações assistenciais "têm-se constituído nas principais demandas" aos assistentes sociais (CFESS, 2009, p. 18). Essas ações devem transpor o caráter emergencial e burocrático da atuação profissional, buscando ter uma direção socioeducativa para com a população usuária dos serviços, visando à potencialização da mesma. Acerca dessa questão, destacamos a seguinte fala do Assistente Social (AS4):

[...] eu acho que nosso papel é esse: tentar viabilizar o que podemos de direito, de se fazer presente no que eles podem receber em termos de orientação, de procedimentos que como eu posso dizer, é de procedimentos e práticas que iram favorecer a sua situação de saúde aqui dentro, a condição de saúde de seu filho.

Nas ações em equipe, o assistente social tem um olhar diferenciado no processo saúde-doença que o torna necessário numa equipe multiprofissional atuante na saúde. Consoante CFESS (2009, p. 21) "[...] o assistente social tem tido, muitas vezes, dificuldades de dialogar com a equipe de saúde para esclarecer suas atribuições e competências face à dinâmica imposta nas unidades de saúde". Assim destaca o entrevistado:

[...] eu acho que todos os profissionais são importantíssimos no atendimento, na recuperação do paciente e tudo, só que, como médico é muito técnico, [...] nós assistentes sociais não abrimos a barriga de ninguém, então o nosso é abstrato, não está ali, é difícil materializar [...] aquilo que falamos subjetivamente com alguém. Então por isso os tecnicistas não dão muita importância ao que a nossa categoria faz. Às vezes até [...] veem a questão da subalternidade,

para isso dimensões ética e operativa. A ação profissional do assistente social na saúde é pautada no direito e na cidadania, numa visão de cidadania estratégica, na busca do direito a ter direito. 


\section{temporolis}

de [a assistente social] ser sua secretaria, essa coisa toda. Então se não fincarmos o pé e dizer a que viemos, acabamos fazendo o que eles querem mesmo (AS-4).

No ambiente hospitalar, a profissão médica ainda é tida como a única categoria autônoma, devido a seu caráter técnico e à sua contribuição objetiva na obtenção do princípio básico que é a recuperação da saúde. Nesse campo, de acordo com a fala acima, há dificuldades nessa relação. Em contrapartida, o Assistente Social (AS-4) relata que há um reconhecimento do trabalho do Serviço Social por outras categorias.

[...] desde quando assumimos, desde quando foi criado [o setor], eu acho que por essa presença constante, trocando ideias com os segmentos do dia a dia, cada um na sua área [...] mas trocando esses saberes com a enfermagem, com o médico, com a psicóloga, tentando sensibilizá-los. [...] então, hoje a nossa categoria é muito reconhecida aqui, o profissional de Serviço Social, muitos chegam até nós e pedem orientação.

É interessante a construção do setor e a conquista de espaço, possível de ser observado considerando a permanente articulação do grupo de assistentes sociais, que se reúnem, discutem seu trabalho profissional e seus desafios e, mais, articulam-se com a equipe multiprofissional. Nessa perspectiva, a Instituição pesquisada apresenta um setor de Serviço Social consolidado, com suas atribuições definidas e reconhecidas pelos outros profissionais e usuários, embora seja um processo, portanto dialético e contraditório, e não homogêneo e estático.

Nas ações socioeducativas, também conhecida como educação em saúde, o assistente social orienta e socializa informações, através de abordagens individuais, grupais ou coletivas à população usuária (CFESS, 2009). Costa (2000) expressa que essa ação acontece no processo de informação das normas e rotinas da instituição. $O$ assistente social atua em todas as etapas do atendimento, a saber: identificação das condições socioeconômicas e sanitárias dos usuários, para agilizar o diagnóstico e o tratamento da doença; reabilitação; alta e/ou encaminhamento, ou óbito, para isso utiliza a linguagem e o conhecimento sobre as leis vigentes. Um dos entrevistados destaca esse aspecto:

Temos também o instrumental que foi criado pelo Serviço Social sobre os direitos, da mãe e do bebê, que tem sobre a 


\section{temporolis}

certidão de nascimento, o teste do pezinho, a importância do aleitamento materno, a licença maternidade, paternidade, com todas as orientações sociais. E tem também o informativo do acompanhante, pelo qual a gente passa todas as orientações dos direitos e deveres dos acompanhantes daqui (AS-3).

Quanto às ações de mobilização, participação e controle social o documento do CFESS (2009, p. 26) destaca:

Estas ações estão voltadas prioritariamente para a inserção dos usuários, familiares e trabalhadores de saúde nos espaços democráticos de controle social e construção de estratégias para fomentar a participação e defesa dos direitos pelos usuários e trabalhadores nos conselhos, conferências e fóruns de saúde e de outras políticas públicas.

Essas ações do Serviço Social da Instituição, ficam restritas à orientação aos usuários quanto à existência da ouvidoria na instituição, quando algum direito daqueles é violado e/ou negado, e ao encaminhamento do usuário para uma instância maior como a Promotoria de Justiça e Defesa da Saúde (PROSUS) ${ }^{12}$, de responsabilidade do Ministério Público, ou seja, é uma ação de socialização das informações e mobilização dos usuários para a luta por melhores condições de vida, de trabalho e de acesso aos serviços de saúde (CFESS, 2009).

Nas ações de investigação, planejamento e gestão, no Serviço Social, destacam-se a elaboração de planos e projetos de ação profissional e a participação nas Comissões e Comitês temáticos como de ética e de humanização, sua participação nesses espaços dá visibilidade para a profissão. Sobre essa ação, percebe-se a consolidação do Serviço Social na Instituição. A equipe está continuamente inserida nos espaços, sempre engajada e por dentro do que acontece no seu local de trabalho.

Por fim, nas ações de assessoria, qualificação e formação profissional, o Serviço Social atua na linha da formação profissional através da supervisão de estágio e do programa de Residência Integrada Multiprofissional em Atenção Hospitalar à Saúde, articulando-se com as demais categorias da saúde, como enfermagem, farmácia, fisioterapia, psicologia e nutrição, bem como com o curso de Serviço Social

12 Paim (2009, p. 129) denomina isso de Judicialização da saúde, “[...] em que os cidadãos buscam no Ministério Público e no Judiciário uma via para o atendimento daquilo que julgam fazer parte do seu direito à saúde." 


\title{
temporolis
}

da Universidade Estadual do Ceará (UECE).

\begin{abstract}
Externamente assim, em nível de nossa imagem fora, o que me retorna, o que eu sei, o que me dizem é que o Serviço Social é reconhecido nos órgãos da categoria e é reconhecido também o Serviço Social da [Instituição] na universidade, na UECE. Eu acho que é um trabalho que nós iniciamos aqui em 1985 [...], acho que conseguimos imprimir uma marca de responsabilidade, sabe, um acompanhamento responsável com os estagiários. Nós tivemos um grande avanço agora com a questão da Residência Multiprofissional, que foi criada no Governo anterior, do presidente Lula (AS-4).
\end{abstract}

Quanto a todas as ações expostas, percebe-se que os assistentes sociais demonstram o compromisso com o Código de Ética de 1993 e a Lei de Regulamentação da Profissão, quando destacam: a importância do trabalho multiprofissional na saúde; a busca pela imposição do que seja a profissão, suas atribuições e funções; o comprometimento da equipe com a garantia e o repasse de informações dos direitos do usuário; o conhecimento de uma gama de serviços sociais que estão na rede, inter-relacionando com a mesma; o engajamento e participação da categoria com todos os espaços na Instituição: Comissões e Comitês, Supervisão de Estágio e Residência Integrada Multiprofissional.

\section{Considerações finais}

O Serviço Social na Instituição pesquisada, desde sua implantação em 1985, vem consolidando seu trabalho profissional nesse espaço sócio ocupacional, refletindo isso no reconhecimento e na legitimidade da categoria perante a instituição e o usuário. É sentido, com isso, o comprometimento da equipe de Serviço Social com o projeto ético-político da profissão, destacando a busca pela qualidade dos serviços prestados; a contribuição na formação acadêmica por ser campo de supervisão de estágio, de pesquisa e do aprimoramento profissional com a residência multidisciplinar.

Percebemos ainda os visíveis de rebatimentos da contrarreforma do Estado no SUS chegando também à Instituição. Isso se expressa no setor de Serviço Social com a redução de sua equipe, a existência do trabalhador polivalente, a sobrecarga de trabalho e a diferenciação dos vínculos empregatícios, fatores que influem efetivamente no cotidiano profissional. 


\section{temporollis}

Mesmo neste contexto de desafios e de contradições no SUS, rebatendo sobre o Serviço Social da Instituição na qual realizamos esta pesquisa, observamos que o Setor de Serviço Social não se abate por essas dificuldades apresentadas, porém, se ratifica como equipe comprometida com um trabalho profissional crítico, ético e engajado com o projeto da categoria, materializado no Código de Ética, reafirmando os direitos dos usuários e buscando dia a dia novas formas de avançar na garantia da gratuidade, universalidade e qualidade dos serviços no campo da saúde.

\section{Referências}

ARAUJO, L. B. de C. A Questão do método em Marx e Lukács: o desafio da reprodução ideal de um processo real. In: MENESES, A. M. D.; FIGUEIREDO, F. F. (Orgs). Trabalho, educação e sociabilidade: uma crítica à ordem do capital. Fortaleza-Ce: Ed. UFC, 2003.

BEHRING, E. R.; BOSCHETTI, I. Política social: fundamentos e história. 4. ed. São Paulo: Cortez, 2008 - (Biblioteca básica de serviço social; v 2).

BRASIL. Lei n. 8.662, de 7 de junho de 1993. Dispõe sobre a profissão de Assistente Social e dá outras providências. Diário Oficial da União, Poder Executivo, Brasília-DF. 8 jul. 1993. Disponível em: < http://www. planalto.gov.br/ccivil_03/leis/L8662.htm> Acesso em: 12 out. 2015.

. Projeto de Lei n. 12317, de 26 de agosto de 2010. Acrescenta dispositivo à Lei n. 8.662, de 7 de junho de 1993, para dispor sobre a duração do trabalho do Assistente Social. Brasília, 2010. Disponível em: <http://www.planalto.gov.br/ccivil_03/_Ato20072010/2010/ Lei/ L12317.htm>. Acesso em: 15 jun. 2011.

CFESS. Conselho Federal de Serviço Social. Resolução CFESS n. 273, de 13 de março de 1993. Institui o Código de Ética dos Assistentes Sociais. Brasília-DF: CFESS, 1993.

. Parâmetros para a atuação de assistentes sociais na saúde (versão preliminar). Brasília-DF: CFESS, 2009.

. Resolução CFESS n. 383, de 29 de março de 1999. Caracteriza o assistente social como profissional da saúde. Brasília-DF: CFESS, 
1999.

. Resolução CFESS n. 493, de 21 de agosto de 2006. Dispõe sobre as condições éticas e técnicas do exercício profissional do assistente social. Brasília-DF: CFESS, 2006.

CNS. Conselho Nacional de Saúde. Resolução n 196, de 10 de outubro de 1996. Diretrizes e normas regulamentadoras sobre pesquisa envolvendo seres humanos. Brasília-DF: CNS, 1996.

CONFEF. Conselho Federal de Educação Física. Resolução n 218, de 6 de março de 1997. O Conselho Nacional de Saúde reconhece os Profissionais de Educação Física como Profissionais de Saúde. Brasília: CNS, 1997.

COSTA, M. D. H. O trabalho nos serviços de saúde e a inserção dos assistentes sociais. Serviço Social \& Sociedade, São Paulo, Ano XXI, n. 62, p. 35-71, mar. 2000.

FONSECA, A. G. A importância do acompanhamento dos recém-nascidos internados na Maternidade Escola Assis Chateaubriand: o olhar materno. 2010. 68 f. Trabalho de Conclusão de Curso (Graduação em Serviço Social)- Universidade Estadual do Ceará, Fortaleza, 2010.

IAMAMOTO, M. V. Relações sociais e Serviço Social no Brasil: esboço de uma interpretação histórico-metodológica. 34. ed. São Paulo: Cortez, 2011.

. Serviço Social em tempo de capital fetiche: capital financeiro, trabalho e questão social. 3. ed. São Paulo: Cortez, 2008.

KRÜGER, T. R. Serviço Social e saúde: espaços de atuação a partir do SUS. Serviço Social \& Saúde, Campinas, v. IX, n. 10, p.123-145, dez. 2010.

LESSA, A. P. G. O trabalho do assistente social no SUS: desafios e perspectivas. In: ; COSTA, L. F. A. da. (Orgs.). o Serviço Social no sistema único de saúde. Fortaleza, CE. Edições UECE, 2003.

LUKÁCS, G. As bases ontológicas do pensamento e da atividade humana. In. Temas de Ciências Humanas. S. Paulo: Livraria Ed. Ciências Humanas, 1978. 


\section{temporalis}

MARX, K. Trabalho alienado e superação positiva da auto-alienação humana. In. FERNANDES, F. (Org.). Marx e Engels: história. São Paulo: Ática, 1989.

MINAYO, M. C. et al. Pesquisa social: teoria, método e criatividade. 25. ed. Petrópolis, RJ: Vozes, 2007.

NOGUEIRA, V. M. R.; MIOTO, R. C. T. Sistematização, planejamento e avaliação das ações dos assistentes sociais no campo da saúde. In: MOTA, A. E.; BRAVO, M. I. et al. (Orgs.). Serviço Social e saúde: formação e trabalho profissional. 2. ed. São Paulo: Cortez, 2007.

PAIM, J. S. O que é o SUS. Rio de Janeiro: Fiocruz, 2009.

PAULO NETTO, J. A construção do projeto ético-político do serviço social frente à crise contemporânea. In. Módulo 1: Programa de Capacitação Continuada para Assistentes Sociais. Brasília-DF: UNB: 1999.

SARRETA, F. O.; BERTANI, I. F. A construção do SUS e a participação do assistente social. Serviço Social \& Saúde, Campinas, v. X, n. 11, p. 31-58, jul. 2011.

SOUSA, C. T. de. A prática do assistente social: conhecimento, instrumentalidade e intervenção profissional. Emancipação, Ponta Grossa, v. 8, n. 1, p.119-132, 2008. Disponível em: < http://www.revistas2.uepg. br/index.php/emancipacao/article/view/119/117 >. Acesso em: 8 maio 2011. 